\title{
AOPs: recent advances to overcome barriers in the treatment of water, wastewater and air
}

\author{
Vítor J.P. Vilar ${ }^{1}$ - Camila C. Amorim ${ }^{2}$ Enric Brillas ${ }^{3}$ - Gianluca Li Puma ${ }^{4}$. \\ Sixto Malato $^{5}$ - Dionysios D. Dionysiou ${ }^{6}$
}

Received: 4 January 2017 / Accepted: 6 January 2017/Published online: 10 March 2017

(C) Springer-Verlag Berlin Heidelberg 2017

Advanced oxidation processes (AOPs) and electrochemical advanced oxidation processes (EAOPs) have been actively tested for water, wastewater, soil and air remediation purposes. These processes generate highly reactive species that are able to effectively promote oxidation and reduction reactions, which are able to remove refractory organic and inorganic species from different type of matrices.

Despite their great potential as green technologies for environmental remediation, AOPs/EAOPs have not yet reached a mature level for large-scale applications. Research efforts have been performed regarding the development of advanced photocatalytic materials absorbing in the visible region, their preparation in the form of structured catalysts, and stabilization on inert surfaces, avoiding a post-treatment for catalysts particles removal. The iron catalysed reactions, principally the

Responsible editor: Philippe Garrigues

Vítor J.P. Vilar

vilar@fe.up.pt

Camila C. Amorim

camila@desa.ufmg.br

Enric Brillas

brillas@ub.edu

Gianluca Li Puma

g.lipuma@lboro.ac.uk

Sixto Malato

sixto.malato@psa.es

Dionysios D. Dionysiou

dionysios.d.dionysiou@uc.edu

1 Laboratory of Separation and Reaction Engineering-Laboratory of Catalysis and Materials (LSRE-LCM), Departamento de Engenharia so-called photo-Fenton or photoelectro-Fenton systems, have attracted wide attention due to their high catalytic activity. Several strategies have been adopted to suppress the barriers regarding the sludge production, acidic $\mathrm{pH}$ adjustments and catalyst consumption through the use of (i) heterogeneous iron reactions using zero-valent iron, iron minerals and iron (hydr) oxides, multimettallic iron-based materials, supported ironbased materials; (ii) photoactive iron complexes with high solubility and reactivity at neutral $\mathrm{pH}$ using chemical additives such as carboxylates, chelating agents and humic-like macromolecules and (iii) continuous dosing of iron or the use of low iron concentrations for applications where the load contaminants is low. Another advance is related to the combination of AOPs/EAOPs with other technologies, such as biological oxidation, adsorption, membranes, ozonation, which makes
Química, Faculdade de Engenharia da Universidade do Porto, Rua Dr. Roberto Frias, 4200-465 Porto, Portugal

2

Denvironmental and Sanitary Engineering,

Universidade Federal de Minas Gerais (UFMG), Belo

Horizonte, Minas Gerais 31270-901, Brazil

3 Departament de Química Física, Facultat de Química, Laboratori d'Electroquímica dels Materials i del Medi Ambient, Universitat de Barcelona, Martí i Franquès 1-11, 08028 Barcelona, Spain

4 Department of Chemical Engineering, Environmental Nanocatalysis and Photoreaction Engineering, Loughborough University, Loughborough LE11 3TU, UK

5 Plataforma Solar de Almería, Carretera Senés Km 4, 04200 Tabernas (Almería), Spain

6 Department of Biomedical, Chemical and Environmental Engineering, 705 Engineering Research Center, Environmental Engineering and Science Program, University of Cincinnati, Cincinnati, OH 45221-0012, USA 
possible to achieve the treatment of contaminants at considerably lower costs.

This special issue of Environmental Science and Pollution Research contains a selection of 45 papers presented at the 8th Meeting on Environmental Application of Advanced Oxidation Processes (VIII EPOA), chaired by Prof. Camila Amorim, and the 2nd Iberoamerican Congress of Advanced Oxidation Technologies (II CIPOA), chaired by Dr. Vítor Vilar, which were held in Belo Horizonte City, Brazil, from 03 to 06 November 2015.

The history of EPOA is since 2001, created by the Research Group of Prof. Dr. Wilson F. Jardim of Environmental Chemistry Laboratory, Institute of Chemistry, Universidade de Campinas, Brazil. From its first edition, the EPOA has attracted a growing number of professionals linked to the multidisciplinary fields of chemistry, engineering, environmental technology and key issues related to pollution removal. The meetings have been held biannually, taking place in Campinas-SP, São Paulo-SP, Santos-SP, Cubatão-SP, Rio de Janeiro - RJ and Recife-PE. The 7th edition, in Recife-PE in 2013 was held in conjunction with the I CIPOA. The idea to combine EPOA and CIPOA was to assemble senior researchers from Iberoamerican countries, allowing more research to be covered, fostering the conference to an international level, as one important forum on study and application of AOPs.

In VIII EPOA/II CIPOA meeting, 248 abstracts were selected as plenary, oral, short-oral or poster presentations and the number of participants was 231. From those 248 abstracts, 133 abstracts were submitted from Brazil and the remaining from Argentina, Spain, Portugal, Chile, Colombia, Ecuador, Venezuela, Peru, USA, France, Germany, UK, India and Pakistan. These indicators are quite good and a bright future can be expected for the meeting.

The review panel of VIII EPOA/II CIPOA, composed by the scientific committee selected the 59 oral presentations and 98 short-oral communications primarily from early-career researchers. The poster session (189 posters) represented an interesting scientific forum, suitable for less formal discussions while enjoying a Brazilian coffee. Also, 12 plenary speakers shared their innovative research work in different topics of advanced oxidation processes.

From the 248 abstracts received, 100 works were selected and submitted as full research papers to the special issue of Environmental Science and Pollution Research Journal, and after rigorous peer-review, 45 of which were accepted for publication.

The topics covered included (i) new photocatalytic materials; (ii) environmental remediation of water, wastewater, air and soil, using different AOPs and EAOPs and (iii) integration of AOPs/EAOPs with other technologies, such as biological oxidation, adsorption, coagulation/flocculation and membranes.

Several papers selected from the scientific presentations of VIII EPOA/II CIPOA outline $\mathrm{TiO}_{2}\left(\mathrm{TiO}_{2} /\right.$ $\mathrm{BiPO}_{4}, \mathrm{TiO}_{2} / \mathrm{Ce}, \mathrm{TiO}_{2} / \mathrm{Pd}$ ) and $\mathrm{ZnO}$ based materials in slurry or immobilized on different inert supports for the degradation of different organic pollutants in water and air. The classical heterogeneous and homogeneous Fenton, electro-Fenton, photo-Fenton, photoelectroFenton, solar driven photo-Fenton processes, catalysed by ferrous iron, ferric iron, magnetic iron species, ferrioxalate complexes, iron oxides and $\mathrm{Fe} / \mathrm{C}$ composites were also evaluated for water and soil remediation. Other types of oxidation processes such as ultrasonic, persulfate, $\mathrm{UVC} / \mathrm{H}_{2} \mathrm{O}_{2}$ and ozonation were also tested for the remediation of water. Other papers dealt with reaction pathways, kinetic modelling, ecotoxicity and inactivation of microorganisms. This special issue also provides an overview of photocatalytic applications and environmental challenges in Iberoamerican countries.

The guest editors would like to thank all the authors for the innovative scientific contributions to this special issue, the reviewers whose comments and suggestions were extremely important to achieve high-quality papers, as well as the institutions and companies that sponsored VIII EPOA/II CIPOA.

We also thank ESPR Editor-in-Chief Philippe Garrigues and the editorial assistants Géraldine Billerot and Marianne Salaün for their assistance/help/support in the preparation of this special issue.

Vitor Vilar wishes to thank the FCT Investigator 2013 Programme (IF/00273/2013) and the financial resources provided by Project POCI-01-0145-FEDER-006984Associate Laboratory LSRE-LCM funded by FEDER through COMPETE2020-Programa Operacional Competitividade e Internacionalização (POCI) — and by national funds through FCT-Fundação para a Ciência e a Tecnologia. Camila Amorim wishes to thank the Organizing Committee, and the support from National Council for Scientific and Technological Development (CNPq), Foundation for Research Support of the State of Minas Gerais (FAPEMIG) and Coordination for the Improvement of Higher Education Personnel (CAPES). Enric Brillas acknowledges financial support from the Organizing Committee and from Universidade de Rio Grande do Norte, Brazil, through an invitation as visitant professor. Sixto Malato wishes to thank the Spanish Ministry of Economy and Competitiveness financial support under the TRICERATOPS Project (Reference: CTQ2015-69832-C4-1-R). Dionysios D. Dionysiou also acknowledges support from the University of Cincinnati through a UNESCO co-chair professor position on "Water Access and Sustainability". 


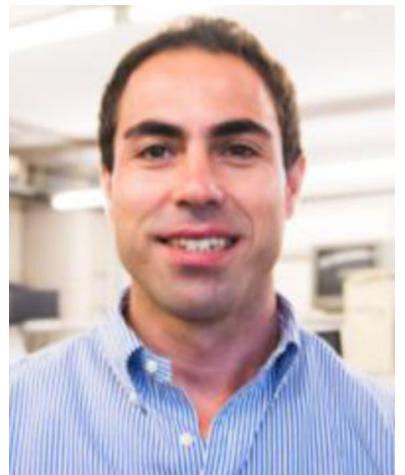

Vítor J.P. Vilar was born in Miragaia, Porto, Portugal in April 1978. He is principal researcher in the Laboratory of Separation and Reaction Engineering-Laboratory of Catalysis and Materials (LSRELCM), Faculty of Engineering, University of Porto (FEUP). He is also "Special Visiting Researcher" in the Federal University of Santa Catarina, Brazil. He received the graduation in Chemical Engineering in 2001 and the Ph.D. in Chemical Engineering in 2006 at FEUP. He is the author and co-author of more than 300 scientific publications, including 2 conference books, 7 book chapters, 140 papers in international scientific periodicals with peer review $(h$ index $=26), 8$ papers in national scientific periodicals and more than 160 communications in conference proceedings, receiving a total of 8 prizes. His main research interests focus in environmental assessment and monitoring of surface waters and environmental friendly technologies for pollution control, including advanced oxidation processes, sorption/biosorption, membrane filtration, biological degradation, process integration \& intensification, water/waste reuse, recycling \& valorization. He has been involved in 5 international, 10 national R\&D projects and 3 contracts with private companies related to the development of environmental friendly technologies for pollution control. V. Vilar is currently one of the editors of Environmental Science and Pollution Research (Springer). V. Vilar completed the supervision of 19 master students, $13 \mathrm{Ph}$.D. students and 15 postdoctoral researchers. Currently, he is the supervisor of 3 master students, $11 \mathrm{Ph} . \mathrm{D}$. students and 7 postdoctoral researchers. He has been teaching at FEUP in several course units of the integrated master in chemical engineering and environmental engineering. $\mathrm{He}$ was also involved in the organization of 3 international scientific conferences and other events/videos for promotion of science and technology. He is also the president of the Iberoamerican Congress of Advanced Oxidation Technologies (CIPOA).

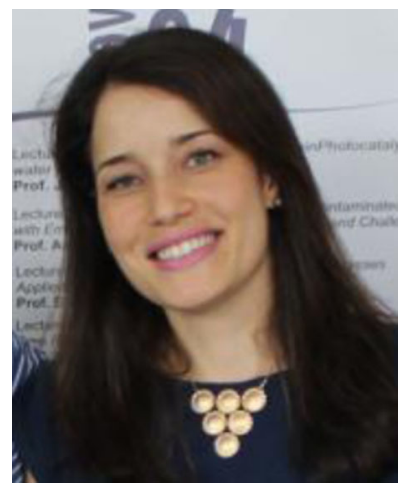

Camila C. Amorim is Associate Professor in Department of Sanitary and Environmental Engineering at the Federal University of Minas Gerais (UFMG). She has a degree in Environmental Engineering from the Federal University of Viçosa and a PhD in Sanitation, Environment and Water Resources at UFMG. Prof. Amorim focus her research on the application of Advanced Oxidation Process for pollution control. She is the principal investigator of GRUPOA - Group of Research an Application of POA in the Pollution Control, that developed projects involving water and wastewater pollution control and environmental impact assessment. He has supervised 8 master students and $3 \mathrm{Ph} . \mathrm{D}$ students. Currently, she is the supervisor of 5 master students and $4 \mathrm{Ph}$.D. students. She has been teaching at UFMG in several course units, mainly in environmental engineering. She is also the president of the 8th Meeting on Environmental Application of Advanced Oxidation Processes (VIII EPOA).

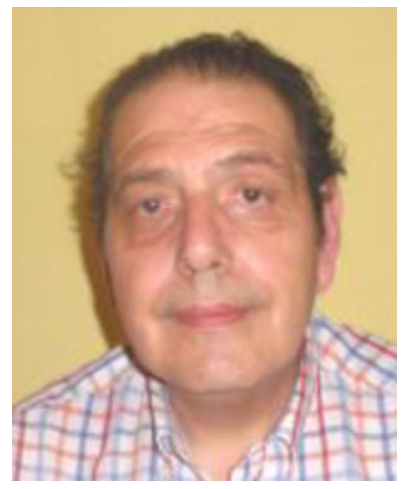

Enric Brillas was born in Barcelona, Spain, in 1951. He obtained his BS degree in Chemistry in 1974 and received his Ph.D. degree in Chemistry in 1977. In 1980, he joined the Universitat de Barcelona as Associate Professor of Physical Chemistry. In 19821983, he completed his studies in electrochemistry at the Università di Padova, Italy, with Prof. E. Vianello in the field of organic electrochemistry. From 1987 to present, he is Full Professor of Physical Chemistry at the Universitat de Barcelona. He was Headmaster of the Department of Physical Chemistry of the Universitat de Barcelona from 2000 to 2008 and President of the Electrochemistry Group of the Real Sociedad Española de Química from 2004 to 2008. Currently, he is Director of the Laboratori d'Electroquímica dels Materials i del Medi Ambient at the Universitat de Barcelona. His research focuses on organic electrochemistry, chemical kinetics, chemical catalysis, photocatalysis, photoelectrocatalysis, electrocatalysis and the electrochemical treatment of organic pollutants. In the latter field, he has developed several electrochemical advanced oxidation processes involving Fenton's reaction chemistry such as electro-Fenton, photoelectroFenton with UV light and solar and peroxi-coagulation. In 1995, he received the international Chemviron Carbon Award and in 2015, he received the CIDETEC 2014 Award for his Work in Electrochemistry. He is Associate Editor of the journal Chemosphere and member of the Editorial Board of the Journal of Hazardous Materials and Applied Catalysis B: Environmental. He has supervised the doctoral theses of 20 Ph.D. students, published 334 peer-reviewed papers with h-index $=60$ (Scopus, September 2016), six books and eleven book chapters, and presented about 280 communications including 35 invited conferences, to scientific congresses. He has participated in 60 research projects.

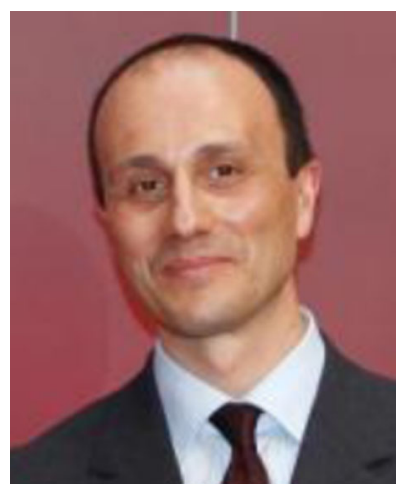

Gianluca Li Puma is Professor of Chemical and Environmental Engineering at Loughborough University and leads "Environmental Nanocatalysis and Photoreaction Engineering" research in the fields of photocatalysis, environmental nanocatalysis, advanced oxidation processes, environmental applications, solar energy conversion and solar engineering. Current research is focusing on process intensification for the removal of contaminants of emerging concern and water reuse using microfluidics technology and oscillatory flow technology. He is Editor of "Journal of Hazardous Materials" (Elsevier). He has participated as committee member or as programme chair in the organization of over 50 international conferences in catalysis, engineering and environmental science for the ACS, IWA and other organizations, and delivered 54 plenary/keynote/invited lectures at international conferences and organisations. He is member of the EPSRC Solar-Fuel Network (UK) and UK Management Committee Member of EU COST Action ES1403UK on New and Emerging Challenges and Opportunities in Wastewater Reuse (NEREUS). 


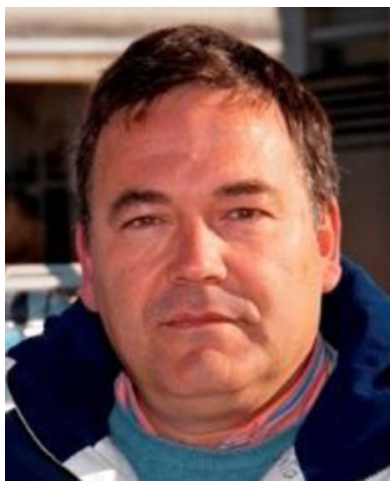

Sixto Malato has 25 years of experience working at different sectors. He works at the Plataforma Solar de Almeria (PSA-CIEMAT) in all the projects linked to solar water treatment. Concretely, he has been involved in $18 \mathrm{EU}$ and 23 National related to the development of solar wastewater treatment technologies, and has been involved in the design and construction of all the experimental pilot plants for solar detoxification of industrial waste water in Europe. He is author of 1 book and co-author of 19 books as well as 64 chapters in others. He has also co-authored more than 230 publications in indexed international journals and 5 patents. He has directed $14 \mathrm{PhD}$ Thesis. Ass. editor Photochemical and Photobiological Sciences. (RSC Publishing), Environmental Chemistry Letters (Ed. Springer), and Journal of Advanced Oxidation Technologies (Sci.\& Technol. Network, Inc.). Member of editorial board: Catalysis Today (Elsevier). h-index (http://www.scopus.com, September 2016): 63 The Jury's Grand Prix of "European Grand Prix for Innovation Awards". 11 December 2004, Mónaco. http://www.european-grandprix. com/index en.htm. Jaime I Price in Environmental Protection, 2011 (Most important in science in Spain). http://www.fvea. es/medioambiente.html.

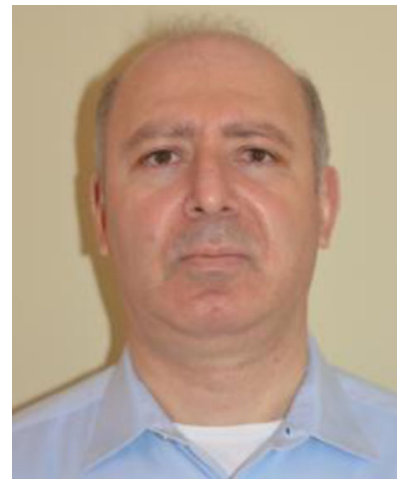

Dionysios D. Dionysiou is currently a Professor of Environmental Engineering and Science Program at the University of Cincinnati. He teaches courses and performs research in the areas of drinking water quality and treatment, advanced unit operations for water treatment, advanced oxidation technologies and nanotechnologies, and physical-chemical processes for water quality control. $\mathrm{He}$ has received funding from NSF, US EPA, NASA, NOAA CICEET, USGS, USDA, Ohio Sea Grant, USAID, and DuPont. He is currently one of the editors of Chemical Engineering Journal, Editor of the Journal of Advanced Oxidation Technologies, and Special Issue Editor of the Journal of Environmental Engineering (ASCE). He is a member of the Editorial Boards of several other journals. Dr. Dionysiou is the author or co-author of over 290 refereed journal publications, over 90 conference proceedings, 20 book chapter publications, 20 editorials, and more than 550 presentations. He has edited/co-edited 5 books on water quality, water reuse, and photocatalysis. He is currently co-editing a book on harmful algal blooms. Dr. Dionysiou's work received over 12,000 citations with an $\mathrm{H}$ index of 60 . Dr. Dionysiou is a fellow of the American Chemical Society (ACS). He is also chair-elect of the Environmental Chemistry Division of ACS and is a member of many committees of several professional societies (i.e., ACS, AEESP, AWWA, WEF, IWA). Dr. Dionysiou has been featured in several international symposia, professional meetings, and scientific publications (i.e., http://ceas.uc.edu/bcee/news/RSC_Highlight.html). 